\title{
DISSENSOS E REPRESENTAÇÕES SOCIOPOLÍTICAS EM OS SETE GATINHOS: CONCEITUANDO A POLÍTICA DO COTIDIANO A PARTIR DE UMA PORNOCHANCHADA
}

\section{DISSENT AND SOCIOPOLITICAL REPRESENTATION IN THE MOVIE OS SETE GATINHOS: CONCEPTUALIZING EVERYDAY LIFE POLITICS FROM THE PERSPECTIVE OF A BRAZILIAN PORNOCHANCHADA}

\author{
Miriam de Souza ROSSINI ${ }^{1}$; Guilherme Fumeo ALMEIDA ${ }^{2}$
}

Resumo: Este artigo problematiza as relações entre o conceito de política do cotidiano e as dinâmicas sociopolíticas expressas nas pornochanchadas, usando como exemplo o filme Os Sete gatinhos (1980), de Neville d'Almeida. Articulando a discussão sobre representação e memória em tempos autoritários em Barraza (1980) e Figueiredo (2017), com a discussão sobre poder em Foucault (1979) e Bourdieu (2009), pretende-se iniciar o diálogo entre a construção do conceito de política do cotidiano e sua aplicação ao objeto fílmico. Foi possível concluir que Os Sete Gatinhos realiza uma estetização e um arquivamento do cotidiano em tempos de autoritarismo político, dentro da representação de uma relação familiar conflituosa, marcada pela performance e pelos dissensos em suas disputas políticas.

Palavras-chave: Pornochanchadas; Política do cotidiano; Os Sete Gatinhos.

Abstract: This article problematizes the relations between the concept of everyday life politics and the sociopolitical dynamics expressed in pornochanchadas, using as example the film Os Sete gatinhos (1980), by Neville d'Almeida. Articulating the discussion on representation and memory in authoritarian times in Barrraza (1980) and Figueiredo (2017), with the discussion about power in Foucault (1979) and Bourdieu (2009), we intend to initiate the dialogue between the construction of the concept of politics of everyday life and its application to the film object. It was possible to conclude that Os Sete Gatinhos accomplishes an aestheticization and an archival of the daily life in times of political authoritarianism, within the representation of a conflictual family relation, marked by the performance and the dissension in its political disputes.

Keywords: Pornochanchadas; Everyday life politics; Os Sete Gatinhos.

\footnotetext{
${ }^{1}$ Doutora em História (UFRGS) e Mestre em Cinema (USP). Graduada em Jornalismo (PUCRS) e em História (UFRGS). Professora Associada do Departamento de Comunicação e do PPG em Comunicação e Informação da Universidade Federal do Rio Grande do Sul (UFRGS). Coordenadora do Grupo de Pesquisa Processos Audiovisuais (PROAv - UFRGS). Bolsista Produtividade do CNPq. Autora de artigos e capítulos de livro sobre cinema brasileiro, cinema e história e sobre as relações entre televisão e cinema no Brasil. Email: miriams.rossini@gmail.com.

${ }^{2}$ Doutorando no Programa de Pós-Graduação em Comunicação e Informação da Universidade Federal do Rio Grande do Sul (PPGCOM-UFRGS). Bacharel em Comunicação Social - Jornalismo e mestre em Comunicação e Informação pela mesma instituição. Integra o Grupo de Pesquisa em Processos Audiovisuais - PROAv-UFRGS. Bolsista CAPES. Email: almeidaguif@gmail.com.
} 


\section{Introdução}

A pornochanchada se consolidou, no Brasil, como o gênero cinematográfico que reunia filmes de diversos estilos, marcados em menor ou menor grau pela junção de erotismo, crítica de costumes e comédia (ABREU, 2002). Dentro da representação de uma cultura erótica nacional, centrada em uma dramaturgia que tematizava elementos de sedução e de humor ambíguo, a pornochanchada também se fortaleceu enquanto gênero cinematográfico de grande sucesso de bilheteria que representava e sofria os reflexos de seu tempo.

Ao longo da década de 1970, este gênero cinematográfico passou por transformações graduais, substituindo o viés cômico, que envolvia a sedução, por uma abordagem de situações cotidianas que uniam drama e erotismo. Este artigo - que se configura enquanto o recorte de uma tese de doutorado em andamento -, parte da análise do filme Os Sete gatinhos (1980), de Neville d'Almeida, para problematizar as relações entre o conceito de política do cotidiano e as dinâmicas sociopolíticas expressas nas pornochanchadas. O filme de Neville d'Almeida, adaptação cinematográfica da peça homônima de Nelson Rodrigues, é um exemplo de pornochanchada que alia a representação do erotismo a uma forte carga dramática e, por isso, nos permite observar as tramas familiares, os seus entornos e os dissensos morais e políticos que tais núcleos aglutinam.

O artigo também propõe iniciar o diálogo entre a construção do conceito de política do cotidiano e sua aplicação ao objeto fílmico, priorizando duas discussões teóricas. A primeira delas discute o papel de narrativas ficcionais na reconstrução da memória e da representação sobre o cotidiano de períodos politicamente autoritários, usando em especial Barraza (1980) e Figueiredo (2017), enquanto a segunda discussão parte de duas perspectivas de poder, em Foucault (1980) e em Bourdieu (2009), para pensar as relações de poder estabelecidas entre os membros de uma família extremamente disfuncional. Enquanto gênero cinematográfico popular, cujos filmes frequentemente levavam milhões de espectadores às salas de cinema (Os Sete gatinhos, por exemplo, teve um público de 1,9 milhões de espectadores), a pornochanchada dava alta visibilidade para a estetização de questões sociopolíticas de seu tempo, tematizando questões sobre as dinâmicas das relações sociais no cotidiano de um período politicamente autoritário. Como a censura voltava-se mais para os aspectos sexuais dos 
filmes, as questões morais, políticas, sociais acabavam sendo menos podadas e, portanto, aparecem de um modo mais cristalino. Assim, a ideia é propor um olhar contemporâneo sobre as representações sociopolíticas dos comportamentos dos indivíduos em seu cotidiano, com seus dissensos, suas performances e disputas constantes, analisando um período recente e politicamente autoritário da história brasileira, sem pretender chegar, neste momento, a uma definição completa do conceito que estamos construindo.

O texto está divido em três partes, além desta introdução e das considerações finais. Na primeira, as especificidades da pornochanchada, enquanto gênero cinematográfico, serão relacionadas à sua abordagem do erotismo e do drama e ao contexto sociopolítico no qual se inseria. Para essa discussão usaremos autores como Simões (2007), Seligman (2000) e Abreu (2002), que estudam este gênero.

As duas partes seguintes vão articular problematização teórica e análise do objeto empírico, dentro de uma proposta metodológica que aplica diretamente a interlocução entre teoria e objeto. Dessa forma, na segunda parte, como ponto de partida para a construção conceitual da política do cotidiano, faremos a discussão sobre o papel da ficção na produção de discursos de representação e memória em tempos de autoritarismo político, relacionando-a com a análise de Os Sete gatinhos enquanto pornochanchada dramática, que tematiza esse cotidiano autoritário. Na terceira parte, por sua vez, proporemos o diálogo entre as duas perspectivas complementares da noção de poder já apontadas, cruzando essas noções de poder com as representações sociopolíticas de Os Sete Gatinhos.

\section{Pornochanchada: erotismo, drama e contexto sociopolítico}

Em sua marca estética e narrativa de união entre humor e erotismo, a pornochanchada valorizou o uso de artifícios como a predominância do olhar masculino, construindo a figura da mulher objeto, e as expressões de duplo sentido. Flávia Seligman (2000) relaciona as bases deste olhar masculino sobre o feminino, calcado na objetificação e nos estereótipos, ao voyeurismo e à exploração do erotismo especialmente a partir da exposição da nudez feminina.

Em relação às expressões de duplo sentido, Inimá Simões (2007) considera-as elemento-chave da formação narrativa do gênero, invertendo sentidos e enriquecendo situações que pareciam banais através de um diálogo bem-sucedido com o público. 
Simões liga o papel do erotismo na pornochanchada à representação dos costumes de uma época, especialmente os ligados à liberação sexual brasileira, com seus limites e especificidades, pela ênfase de situações envolvendo conquistas amorosas, adultério e virgindade.

Nuno Cesar Abreu (2002) também vincula o erotismo da pornochanchada a um determinado contexto social e considera-o uma comercialização de versões sobre questões sociais e sexuais dos anos 1970 e início dos 1980. Por meio desta lógica de comercialização, a construção narrativa dos filmes do gênero continha a apresentação e a resolução de algum conflito sexual, com o seu desfecho resultando em elementos eróticos como sedução e voyeurismo, não raro acompanhados de formas de violência. A partir do final dos anos 1970, tal lógica aproximou o gênero de uma abordagem mais dramática, em que um contexto político de ditadura, com autoritarismo político e crise econômica, era refletido em títulos que substituíam a leveza da comédia erótica pelo drama sexual, passando a unir o desencanto social e o sexo de formas muitas vezes trágicas. Como exemplos, além de Os Sete Gatinhos, se destacam pornochanchadas de final da década de 1970 e início dos anos 1980, como Nos Embalos de Ipanema (Antônio Calmon, 1978) e A Noite das Taras (David Cardoso, Ody Fraga e John Doo, 1980).

Em relação ao Brasil politicamente autoritário da década de 1970, recorre-se a um texto próximo ao período e outro contemporâneo, construindo uma complementariedade entre olhares internos e externos ao período em análise. Segundo Sebastião Velasco e Cruz e Carlos Estevão Martins (1984), o regime autoritário deu protagonismo às classes dominantes no processo de desenvolvimento nacional, com o crescimento econômico tendo consequências crônicas, que geraram uma crise profunda no final da década de 1970. Assim, ao mesmo tempo em que a economia brasileira crescia em altas taxas anuais, como 8,8\% em 1970, 13,3\% em 1971 e $14 \%$ em 1973, havia o custo do arrocho salarial, da inflação e do endividamento interno e externo. Enquanto esta crise não se tornou perceptível, o elevado crescimento econômico foi fundamental à propaganda oficial de força, dinamismo e paz de um regime que, por trás de sua imagem oficial, tornou assassinatos, torturas e sequestros práticas de Estado, aliando ordem e medo. 
Angelo Priori et al (2012) destacam o esforço do regime autoritário em salvaguardar o trabalho das forças repressivas por trás de um discurso de ordem e de defesa da democracia, com a criação de órgãos de repressão, como o Serviço Nacional de Informações (SNI) e os Destacamentos de Operações de Informação - Centros de Operações de Defesa Interna (DOI-CODI), além do fortalecimento dos Departamentos de Ordem Política e Social (DOPS) em todos os Estados. Este discurso criou uma atmosfera de ufanismo, ao mesmo tempo em que grupos ligados a movimentos de guerrilha "urbana e rural foram sendo progressivamente eliminados. A repressão desencadeada na época atingiu centenas, talvez milhares de pessoas envolvidas com a luta armada" (PRIORI ET AL, 2012, p. 203). Esta atmosfera política e social opressiva foi acrescida, desde fins dos anos 1970, de um contexto de crise econômica e de descrença. O milagre econômico havia chegado ao fim e a abertura política ainda era uma promessa.

Neste contexto, o diálogo entre a pornochanchada e a dinâmica de seu tempo ia além da abordagem erótica, incluindo os efeitos das problemáticas econômicas, sociais e políticas pelo ponto de vista das classes populares. Esta inclusão resultou em uma fusão da "ideologia dos seus produtores e consumidores, imersa num devorador processo econômico controlado por um rígido processo político" (ABREU, 2002, p. 183). Assim, apesar de privilegiar uma lógica comercial e não contestatória, em tempos de censura, o gênero não deixou de refletir o espírito do seu tempo, fíccionalizando a experiência cotidiana dos indivíduos em uma época politicamente autoritária e socialmente conservadora, com esta ficcionalização sendo disseminada pelo diálogo da pornochanchada com seu grande público. Através do acesso a milhões de espectadores em seus diversos filmes, dentro de um sistema que gerou uma produção robusta e plural de longas-metragens por mais de uma década, o gênero se consolidou como uma vitrine das discussões sociopolíticas do seu tempo.

Dentro do privilégio desta experiência, além da abordagem performática do sexo, as pornochanchadas utilizavam o deboche social através de uma crítica superficial às relações interpessoais no dia-a-dia das cidades brasileiras. Para Jean-Claude Bernardet (2009, p. 209), este deboche emprega o sexo como metáfora para tratar da "sociedade global em que vivem os espectadores da pornochanchada. Essa guerra, esse sexo técnico e quantitativo, esse desprezo pelo outro, essa valorização do capaz contra o 
incapaz e ineficiente são traços da vida social". A abordagem do deboche se consolidou como um traço essencial do gênero, permanecendo mesmo quando ele passou a privilegiar um viés mais dramático do erotismo em detrimento do humor. Erotismo e escárnio, na pornochanchada, são inseparáveis: o que muda, nas fases cômica e dramática, são a ênfase nos conflitos sexuais e suas resoluções, geralmente culminando em ironia e calmaria, na primeira, e em situações não raro ligadas a violências e morte, na segunda. Essas são questões que vão permear, de um modo enfático, o cotidiano retratado nas narrativas desse gênero cinematográfico, já que não estão voltadas para o consumo familiar.

\section{Marcas do autoritarismo na pornochanchada: ficção, memória e política}

Ao privilegiar a dinâmica do cotidiano em tempos autoritários, em uma análise que toma como ponto de partida o contexto chileno de ditadura militar, Ximena Barraza (1980) destaca a capacidade da imaginação artística em captar as especificidades da vida cotidiana sob a ordem autoritária, assimilando as subjetividades que se materializam enquanto efeitos da vivência dos indivíduos em tempos de autoritarismo político. Problematizando esta capacidade das manifestações artísticas, como as fícções cinematográficas, é possível apreender as consequências da ordem autoritária no dia a dia, como o ensimesmamento e o fechamento em dinâmicas familiares, dentro de uma falta de comunicação mais completa dos indivíduos com seu espaço e seu tempo. Este processo, para Barraza, também está relacionado ao disciplinamento de cada relação social, fazendo com que todas elas sejam economicamente rentáveis e politicamente dominadas, dentro de um processo abrangente de pacificação e domesticação.

Em Os Sete Gatinhos, ao tentar se impor a todo custo como chefe de família, perante a esposa e as filhas, ao mesmo tempo em que se sente fracassado por sua posição social subalterna, Noronha é inserido em um impasse, que está diretamente relacionado com os conflitos da trama. Este impasse e suas consequências para a dinâmica familiar exemplificam o destaque feito por Barraza da capacidade da imaginação artística de captar as dinâmicas da vida cotidiana sob a ordem autoritária, assimilando as subjetividades que se materializam enquanto efeitos da vivência dos indivíduos em tempos de autoritarismo político.

Ao destacar a noção de arquivo como uma forma de analisar as relações entre memória e esquecimento no contexto brasileiro pós-ditadura militar, Eurídice 
Figueiredo (2017), por sua vez, elabora uma proposta para se pensar a ficção como resgate e ressignificação da violência que é fruto do autoritarismo estatal ou que está indiretamente relacionada a ele. No caso nacional, Figueiredo aponta uma cultura dos vestígios em um contexto de falta de memória, que supriria, através das potencialidades ficcionais, a falta de um arquivo efetivo que permitisse o acesso aos traumas e abusos ocorridos no recente passado autoritário.

A autora ressalta a capacidade da ficção de escavar camadas e detectar lembranças, a partir do exemplo da literatura, mas que pode ser transposta para peças ficcionais de outros meios, como o cinema. Assim, através da criação de personagens e da simulação de situações, segundo Figueiredo (2017, p. 29), "o escritor é capaz de levar o leitor a imaginar aquilo que foi efetivamente vivido por homens e mulheres".

Em seu registro de uma perspectiva política do cotidiano de uma família de classe média baixa em meio a um contexto de autoritarismo político não mencionado diretamente, Os sete gatinhos manifesta esta capacidade ficcional de resgatar e ressignificar a violência em tempos autoritários destacada por Figueiredo, mostrando-se enquanto um registro do espírito de um determinado tempo, sobre o qual se configura enquanto um documento ficcional e um exercício de memória. $O$ filme faz uma representação dos dramas familiares durante a ditadura militar brasileira a partir da decadência moral de Noronha e sua família, fundindo a problematização do controle paterno com o declínio deste domínio dentro do ecossistema familiar.

Construído no filme enquanto uma mercadoria e um instrumento de manipulação dos mecanismos de dominância nos quais estão inseridos Noronha (Lima Duarte), Aracy (Thelma Reston) e as filhas - Silene (Cristina Aché), Aurora (Ana Maria Magalhães), Arlete (Regina Casé), Hilda (Sura Berditchevsky) e Débora (Sônia Dias) -, o corpo feminino também se vincula às engrenagens estéticas e narrativas ligadas ao gênero cinematográfico a que Os sete gatinhos pertence. Como aponta Seligman (2000), uma destas engrenagens é a valorização do olhar masculino em relação às figuras femininas, dentro da ideia de mulher objeto, com a exposição do corpo feminino calcado na objetificação e nos estereótipos.

Abreu (2002) relaciona esta construção de um olhar masculino sobre a mulher da pornochanchada a uma construção narrativa cujo desfecho se liga a um forte teor erótico, em que geralmente estavam contidos o voyeurismo e alguma forma de 
violência. Estes dois pontos se tornaram ainda mais presentes desde final dos anos 1970, quando as pornochanchadas passaram a valorizar tramas dramáticas em detrimento do humor, como no caso de Os sete gatinhos, e sua trágica saga de uma família de mulheres dominada pela violência - simbólica e efetiva - e pela frustração do patriarca.

Esta dinâmica de autoridade, representada pelo filme por meio de sua capacidade de captar e arquivar os rastros do cotidiano em tempos de autoritarismo político, se vincula às especificidades do seu gênero cinematográfico na abordagem dos efeitos de questões econômicas, sociais e políticas pela vivência das classes populares em seu dia a dia. Dentro desta abordagem, o uso performático da temática sexual se une ao deboche social, como destaca Bernardet (2009, p. 209), dentro de uma metáfora em que sexo é sinônimo de desprezo pelo outro e do comando do capaz sobre os menos capazes ou poderosos em um determinado contexto social, como o em que se insere a família de Noronha.

Este processo dialoga com a análise de Barraza (1980) sobre o disciplinamento das relações sociais em tempos de autoritarismo político, que ordena cada relação social dentro de uma lógica de rentabilidade econômica e dominação política. Nesse contexto de tentativa de domesticação familiar pela figura paterna e de representação das dinâmicas sociais e eróticas do cotidiano através do deboche, ao reverter a ordem moral familiar na transformação do lar em bordel e buscar manter seu controle nesta ordem, Noronha acaba por facilitar inconscientemente sua própria deposição do posto de dominância. Ao matar Bibelot e se revelar como o culpado pelas agruras morais da própria família, o patriarca é extinto como modelo de comando pela esposa e as filhas.

Primeiro apunhalado por Arlete, Noronha é morto dentro de um momento de gozo das mulheres da família, uma vingança com traços de devoração quase que de fato, deixando explícito o dissenso moral e de poder no núcleo familiar. Após a morte do pai e com a consagração do colapso do pátrio poder, como destaca Ismail Xavier (2003, p. 194), "as mulheres assumem o comando, e a Gorda, em consonância com a fartura de peitos e poses fellinianas, assume a direção do bordel e põe as filhas à venda num mercado que agora se desenha como uma utopia carnavalesca". Xavier define este processo como a resposta feminina à crise familiar, com o drama entre as perspectivas de Noronha e as disposições de Silene, com seu sexo precoce e a crueldade do 
assassinato da gata grávida precipitando a revelação de verdades que culmina na descoberta da culpa paterna.

No entanto, essa troca de poder não significou uma troca de modelo de comando. Num ambiente autoritário, as figuras no poder são intercambiáveis, e o que se mantém é a obediência à ordem. Nessa construção de um olhar sobre a decadência moral da família suburbana, Os Sete Gatinhos opera um registro, enquanto pornochanchada dramática, de um espírito do tempo autoritário, em que moralidade, dominância e mercantilização se unem para a consolidação de um tipo de ordem, de um tipo uma política do cotidiano familiar.

\section{Relações de dominância e processos de sujeição individual em Os Sete Gatinhos}

Pensando na problematização do conceito de política do cotidiano por meio do diálogo com a noção de poder, serão consideradas duas perspectivas da noção, a de Pierre Bourdieu (2009) e a de Michel Foucault (1979), vistas dentro de um conjunto complementar. Na perspectiva de Bourdieu (2009), o poder simbólico é definido enquanto um instrumento silencioso de construção da realidade que tende a consolidar uma ordem de sentido do mundo social. Dentro desta consolidação, o papel das ideologias é fundamental por representarem interesses particulares camuflados de coletivos e que impactam na configuração das relações de poder.

A função política do poder simbólico, por sua vez, é desempenhada pelos sistemas simbólicos, instrumentos de imposição ou de legitimação de formas de dominância de violência simbólica (de uma classe em relação a outra, por exemplo) e de domesticação que suavizam as relações de força na forma das relações de sentido. Através deste efeito suavizador, o poder simbólico produz crenças e transforma a visão e a ação em relação ao mundo - e o próprio mundo, portanto. Para ser efetivo, contudo, este poder embasado no consenso e na substituição da força pela mobilização precisa do reconhecimento social de sua legitimidade, o que ocorre dentro de uma "relação determinada - e por meio desta - entre os que exercem o poder e os que lhe estão sujeitos, quer dizer, isto é, na própria estrutura do campo em que se produz e se reproduz a crença" (BOURDIEU, 2009, p. 15).

Em Os Sete Gatinhos, o espaço principal de exercício do poder é um ambiente familiar: a casa de classe média baixa no subúrbio do Rio de Janeiro, onde o contínuo da Câmara dos Deputados, Noronha, vive com a esposa, Aracy, a quem chama de 
Gorda, e as cinco filhas, como já dito. Ao fundir a problematização do poder paterno com a decadência moral dele e de sua família, o filme permite uma análise dos limites e do alcance da noção de poder simbólico, apresentando Noronha como chefe de família, autoritário, moralista e irritadiço, oscilando entre a violência e o exercício mais sutil de poder de quem deseja se impor perante a esposa e as filhas, ao mesmo tempo em que se sente fracassado por sua posição social subalterna.

Dentro desta oscilação, Noronha muitas vezes não consegue consolidar, dentro da ideia do poder simbólico, uma posição de chefe de família que une as demais em torno de suas vontades, como quando inquire a esposa e as filhas sobre os desenhos de pênis feitos no banheiro - que dentro do clima de pornochanchada do filme, gera a fala característica do moralista indignado: "quem foi que desenhou caralhinhos voadores na parede do banheiro?". Nenhuma delas se acusa ou acusa a culpada, e Noronha, frustrado, se exalta ao ver que suas capacidades de domínio mais sutil sobre a situação familiar falharam, discutindo com uma das filhas, Arlete (Regina Casé), batendo nela após ser chamado, com desprezo, de contínuo.

Ao mesmo tempo, até certo momento da trama, Noronha tem sucesso em mobilizar a família em torno da consagração da pureza da filha caçula, Silene (Cristina Aché), através de um casamento imaculado e com enxoval completo, sacrificando assim a situação moral e material das outras filhas, que se prostituem em prol do enxoval da irmã. Em sua imposição de moralidade, por um lado, e pelas concessões imorais em defesa desta obstinação, por outro, o contínuo consegue, até certo ponto, impor as ideias de dominância e domesticação dos sistemas simbólicos.

Conforme Bourdieu, o funcionamento do poder simbólico está ligado à integração dos indivíduos com o mundo social, dentro de um processo de cumplicidade entre suas atitudes e sua posição - o que consolida a posse do possuidor por aquilo que ele possui, ou acredita ter legitimidade em possuir ou deseja continuar possuindo, com suas ações moldadas por essas crenças. A vontade de dominar, assim, surge como resultado do próprio sistema de dominância e de um movimento de defesa dos seus privilégios a partir da pressão feita pelos menos privilegiados, dentro deste jogo de dominância no qual embarcam tanto os que exercem posições de dominação quanto os que são mais dominados, aceitando uma série de imposições, de forma inconsciente, mas que estão ligadas ao funcionamento deste jogo. 
Esta camuflagem bem-sucedida das relações de força por parte do poder simbólico também impacta na transmissão dos efeitos ideológicos, por meio de instrumentos como o corpo. Pela consolidação da manipulação corporal, funcionam diversos mecanismos efetivos de dominância, principalmente em relação às mulheres, padronizando modos andar, falar e esconder determinadas partes do corpo, como os seios.

Figura ambígua de dominância em Os Sete Gatinhos, Noronha, ao vincular o código moral da família à pureza de Silene, vê as bases já pouco sólidas de sua dominância familiar gradativamente ruírem conforme estes ideais morais passam a se revelarem falsos, a partir do retorno da filha caçula à casa familiar. Ela volta do colégio interno em que estudava ao lado de um funcionário da escola (Ary Fontoura), que ao revelar para Noronha que Silene foi expulsa da instituição após matar a pauladas uma gata que deu à luz a sete filhotes, sente a ira do pai que vê publicamente desmontados os ideais de pureza que forjou para a jovem.

Em sua revolta, o patriarca mobiliza as mulheres da família para defenderem a inocência da caçula ante a mentira do funcionário do colégio, mas a própria Silene admite a culpa, e a ameaça de Noronha de esfaquear o homem, demonstração patriarcal de poder e de defesa de honra familiar, não é concretizada. $\mathrm{O}$ funcionário do colégio é expulso da casa pelas filhas, e o pai continua a ver Silene como imaculada, mas o poder de Noronha enquanto defensor da pureza logo passa por novo baque: o médico da família, Dr. Bordalo (Cláudio Corrêa e Castro), examina a caçula, e revela a gravidez. Em sua demonstração de poder e defesa da própria legitimidade de se manter como dominante na ordem familiar, o patriarca decide transformar a modesta casa de subúrbio em prostíbulo e as filhas em prostitutas, começando por oferecer Silene a Bordalo. Assim, Noronha passa a prostituir a mesma honra que insistiu em proteger, usando-a como moeda de barganha para manutenção do seu poder e se transformando, de contínuo, em cafetão da pureza familiar.

Ele encontra dessa forma a sua distinção, a sua existência dentro do mundo social dentro do que Bourdieu (2009) define enquanto representação e vontade. O patriarca se renova dentro de sua vontade de manter sua posição de dominância e sua representação de chefe familiar, com o uso literal do corpo das filhas, em termos materiais, para um uso ideológico, de manutenção de poder, e é inicialmente aceito pela 
esposa e pelas filhas enquanto tal, em um aparente consenso dentro do espaço de relações da família, a casa metamorfoseada em bordel. Além de prostituir as fillhas neste espaço, tendo como clientes homens da vizinhança, como o médico e o quitandeiro, Noronha envia-as para missões externas, como quando pede para Arlete ir à casa de um deputado (Maurício do Valle), sem explicar a ela o propósito da visita.

Ao reverter a ordem moral familiar e buscar manter seu poder dominante, contudo, Noronha acaba, acidentalmente, por criar as condições para sua própria deposição deste posto de dominância: descobrindo que seu amante, o malandro Bibelot (Antonio Fagundes), é o mesmo homem com quem Silene perdeu a virgindade e que engravidou a irmã, Aurora (Ana Maria Magalhães) conta ao pai e leva Bibelot para uma armadilha na casa familiar. Fazendo a esposa e as filhas acreditarem que aquele era o culpado pela desgraça da família, o homem que chorava apenas por um olho, conforme um oráculo lhe havia revelado em sessões espíritas, Noronha apunhala Bibelot, que chora não por um, mas pelos dois olhos. Inocentado o malandro após a morte, a esposa e as filhas voltam-se enfim contra o patriarca, acusando-o de assassino e cafetão e, ao verem-no caído na mesa chorando apenas por um olho, consagram sua revolta pela extinção, a facadas, do verdadeiro culpado da desgraça moral e material familiar.

Nos estudos de Foucault (1979), por sua vez, a ênfase nos mecanismos de dominação e manutenção do poder, privilegiada pela perspectiva do poder simbólico de Bourdieu, é substituída pelo estudo das diversas configurações do poder nas sociedades capitalistas. Assim, a análise do poder pelo seu lado interno, pela sua intenção, pela busca de como age quem detém o poder, dá lugar à problematização do poder em sua face externa, materializado em práticas concretas e contextualizado nos ambientes em que ele se localiza e produz efeitos.

Ao problematizar as especificidades desta faceta externa do poder, a perspectiva foucaultiana atenta para o funcionamento dos processos de sujeição dos corpos e de orientação dos comportamentos sociais, em um esforço de compreensão da constituição dos sujeitos face a um poder que não se divide entre possuidores e despossuídos. $\mathrm{O}$ poder circula, funcionando através de um processo em rede e não podendo ser cooptado por um determinado grupo, constituindo uma complexa cadeia de relações. Nesta cadeia, os indivíduos também circulam enquanto aqueles que tanto exercem e sofrem a ação do poder, se configurando enquanto seus centros de transmissão. O poder, dessa 
forma, não se aplica ao indivíduo, mas passa por ele, que é "um efeito do poder e simultaneamente, ou pelo próprio fato de ser um efeito, é seu centro de transmissão. $O$ poder passa através do indivíduo que ele constituiu (FOUCAULT, 1979, p. 183 e 184).

Problematizando esta perspectiva de análise do poder em Os Sete Gatinhos, a ideia de dominação familiar por Noronha é substituída pelos processos de sujeição e orientação dos comportamentos do contínuo, da esposa e das filhas e a ligação deles com a circulação de poder entre estes indivíduos. Neste contexto, a defesa da pureza de Silene deixa de ser um instrumento de dominação familiar de Noronha para ser um elemento nesta cadeia de relações em que todos podem tanto sofrer quanto exercer o poder e na qual abre-se espaço para momentos de reviravolta e ambiguidade.

Um destes momentos ocorre quando Noronha confronta a esposa e as filhas sobre os desenhos de pênis no banheiro. Desde o início do interrogatório paterno, Arlete assume uma posição de confronto e deboche: vestindo sutiã e calcinha pretos, ela grita que ninguém fez os desenhos. Vendo nela a representação da afronta, da negativa das mulheres da família em revelar a autoria dos desenhos, Noronha fica cada vez mais exaltado, dando dois tapas na filha após ser chamado de contínuo. As redes de poder, na linguagem desta família, são dinâmicas, e após ser agredida pelo pai, Arlete se ergue do sofá e se apresenta como agente do poder, gritando novamente a Noronha - “É! É! Contínuo sim. Eu disse con-tí-nuo!" - e sentando no sofá com as pernas abertas. Resignado e momentaneamente derrotado, o pai embarca em um lamúrio, decepcionado com as filhas socialmente fracassadas, que ainda não se casaram, e lamenta o que vê como desgraça familiar.

$\mathrm{Na}$ perspectiva foucaultiana, os mecanismos de controle e repressão da sexualidade são instrumento de poder, e têm grandes impactos políticos e econômicos. Dentro desse quadro, o sexo, para Foucault, se inclui na produção do dispositivo de sexualidade, que foi inicialmente aplicado ao corpo, aos órgãos sexuais e aos prazeres para depois ser ligado ao sexo em si. Como resultado, se formou um conjunto heterogêneo de sentidos que, permeado pelo discurso de sexualidade, tornou o sexo enquanto elemento principal de seu próprio discurso e sentido.

Em Os Sete Gatinhos, os mecanismos de controle e repressão da sexualidade têm seu símbolo principal nos efeitos do moralismo obsessivo de Noronha em torno da pureza de Silene. Ela deveria se manter imaculada até o casamento e, quando sua 
gravidez é descoberta, o pai continua a controlar a sexualidade dela e das outras filhas tornando-as prostitutas dentro da própria casa, com o bordel familiar simbolizando esta repressão. A sexualidade, aqui, rege o corpo e o sexo, com a prostituição forçada sendo uma punição da instância de controle paterna à fuga da norma, simbolizada na ideia de pureza, e no sexo de Silene com Bibelot. É a punição do prazer com outra forma de controle, a da prostituição, sendo o primeiro negado, como se o sexo com prazer fosse uma forma de escapar ao controle da sexualidade por parte da norma, da figura de controle, que tenta readequar o conjunto de forças até o momento em que este controle será, por fim, extinto.

Esta extinção ocorre com a reviravolta da descoberta por Aracy e suas filhas da culpa de Noronha - o resultado é um movimento de revolta que termina com o assassinato do patriarca, a facadas. Findo o controle familiar de Noronha, contudo, seu projeto sexual e doméstico permanece, agora sob o controle de sua viúva, que mantém a casa-bordel em pleno funcionamento. Em Os Sete Gatinhos, portanto, é destacada a ideia de mercantilização da mulher, dentro da linguagem do gênero cinematográfico ao qual o filme pertence e da continuidade de um controle social sobre o corpo e a sexualidade, especialmente a feminina.

\section{Considerações finais}

Ao longo deste artigo, demos início à problematização do conceito de política do cotidiano a partir da análise das representações sociopolíticas de Os Sete Gatinhos sobre os comportamentos cotidianos dos indivíduos em tempos de autoritarismo político. Dentro desta interlocução entre conceito e objeto, foi elaborada uma análise que não chegou a uma definição completa em relação à política do cotidiano, mas, sim, relacionou-a com os sentidos expressos por Os Sete Gatinhos enquanto pornochanchada dramática, cujo gênero cinematográfico estabeleceu um determinado diálogo com seu contexto sociopolítico e com seu público, em torno de questões comportamentais do dia a dia de sua época.

A partir da relação entre a capacidade ficcional de apreender as consequências da ordem autoritária no cotidiano, se fortalecendo como instrumento de memória, e as representações sociopolíticas em tempo de ditadura civil-militar expressas em Os Sete 
Gatinhos, foi possível relacionar pontos como o impasse de Noronha, que tenta impor uma condição de dominância familiar, com o destaque de Barraza (1980) da assimilação das dinâmicas da vida diária sob a ordem autoritária pela ficção. Esta assimilação é demonstrada pelo filme, enquanto pornochanchada que aborda os efeitos das questões econômicas, sociais e políticas no cotidiano dos indivíduos, em sua estetização, captação e arquivamento dos rastros dessa rotina em tempos de autoritarismo político. Em sua apresentação dos dramas familiares durante a ditadura militar brasileira a partir da decadência moral de Noronha e sua família, Os Sete Gatinhos expõe um processo de disciplinamento das relações sociais a partir de uma dinâmica de rentabilidade econômica e dominação política.

Já sobre o diálogo entre as duas perspectivas complementares de poder e a análise das dinâmicas do cotidiano familiar expressas pelo filme, detectamos a consolidação da construção de uma relação conflituosa de dominância entre Noronha, esposa e filhas, marcada pela performance e pelos dissensos nas disputas políticas na rotina desta família, dentro da ideia de Bourdieu (2009) de poder simbólico e construção da realidade que tende a consolidar uma ordem de sentido do mundo social, culminando na extinção da figura de dominância masculina a punhaladas. Com base na perspectiva foucaultiana de orientação dos comportamentos sociais e da circulação de um poder em rede, a ideia de dominação familiar por Noronha é substituída pelos processos de sujeição e orientação dos comportamentos do contínuo, da esposa e das filhas e a ligação deles com a circulação de poder entre estes indivíduos. Neste contexto, todos podem tanto sofrer quanto exercer o poder, abrindo espaço para a reviravolta final da trama, em que Noronha é morto pelas filhas e pela esposa, que assume o controle da casa-bordel familiar, e dessa forma continua a negar às próprias filhas o direito à liberdade individual.

\section{Referências}

ABREU, Nuno Cesar. Boca do Lixo: cinema e classes populares. Campinas/SP: Editora da Unicamp, 2002.

BARRAZA, Ximena. Notas sobre a vida cotidiana numa ordem autoritária. In: MAIRA, Luís et. al. América Latina: novas estratégias de dominação. Petrópolis: Vozes, 1980. p. 135-167.

BERNARDET, Jean Claude. Cinema Brasileiro: propostas para uma história. São Paulo: Companhia das Letras, 2009. 
BOURDIEU, Pierre. O Poder Simbólico. Rio de Janeiro; Bertrand Brasil, 2009.

CRUZ, Sebastião Velasco e MARTINS, Carlos E. De Castello a Figueiredo: uma incursão na pré-história da Abertura. In: SORJ, Bernardo e ALMEIDA, Maria Hermínia T. (orgs.). Sociedade e política no Brasil pós-64. São Paulo: Brasiliense, 1984.

FIGUEIREDO, Eurídice. A literatura como arquivo da ditadura brasileira. Rio de Janeiro: 7 letras, 2017.

PRIORI, A., et al. A Ditadura Militar e a violência contra os movimentos sociais, políticos e culturais. In: História do Paraná: séculos XIX e XX. Maringá: Eduem, 2012.

FOUCAULT, Michel. Microfísica do poder. Rio de Janeiro: Edições Graal, 1979.

SELIGMAN, Flávia. O "Brasil é feito pornôs": o ciclo da pornochanchada no país dos governos militares. Orientadora: Maria Dora Genis Mourão. Tese (Doutorado) - Universidade de São Paulo, Escola de Comunicações e Artes, Departamento de Pós-Graduação, São Paulo, BR-SP, 2000.

SIMÕES, Inimá. Sexo à brasileira. Revista ALCEU - v.8, n.15, jul./dez. 2007.

XAVIER, Ismail. O olhar e a cena - Melodrama, Hollywood, Cinema Novo, Nelson Rodrigues. São Paulo: Cosac Naify, 2003. 